\title{
Slip distribution of the 1973 Nemuro-oki earthquake estimated from the re-examined geodetic data
}

\author{
Takuya Nishimura \\ Geography and Crustal Dynamics Research Center, Geographical Survey Institute, Kitasato 1, Tsukuba, Ibaraki 305-0811, Japan
}

(Received February 27, 2009; Revised July 3, 2009; Accepted August 17, 2009; Online published December 21, 2009)

\begin{abstract}
Geodetic data, including leveling, tide-gauge, triangulation/trilateration, and repeated EDM data, from eastern Hokkaido, Japan, were re-examined to clarify the crustal deformation associated with the 1973 Nemuro-oki earthquake. We inverted the geodetic data to estimate the slip distribution on the interface of the subducting Pacific plate. The estimated coseismic slip, potentially including afterslip, showed a patch of large slip (i.e., an asperity) near the epicenter of the mainshock. The moment magnitude of the Nemuro-oki earthquake was estimated to be 8.0 from the geodetic data, which is comparable to the $2003 M_{\mathrm{w}}=8.0$ Tokachi-oki earthquake. The estimated slip distribution suggests a $50 \mathrm{~km}$-long gap in the coseismic slip between the 1973 Nemuro-oki and the 2003 Tokachi-oki earthquakes. The slip area of the $2004 M_{\mathrm{w}}=7.0$ Kushiro-oki earthquake, estimated from GPS data, was located at the northwestern edge of the Nemuro-oki earthquake, which implies that the area may have acted as a barrier during the Nemuro-oki earthquake. The postseismic deformation observed by leveling and tide-gauge measurements suggests that the afterslip of the Nemuro-oki earthquake occurred at least in a western and northern (i.e., deeper) extension of the asperity on the plate interface.
\end{abstract}

Key words: Kuril Trench, Nemuro-oki earthquake, slip distribution, geodetic data.

\section{Introduction}

The Kuril Trench is known as one of the most intensive areas of seismic activity in the world. This activity is caused by the rapid convergence $(7-9 \mathrm{~cm} / \mathrm{yr}$ ) between the subducting Pacific plate and the overriding Okhotsk (or North America) plate (e.g., Sella et al., 2002). The June 17, $1973 M_{\mathrm{w}}=7.8$ Nemuro-oki (Nemuro-Hanto-oki) earthquake occurred along a southwestern part of the Kuril Trench, southeast of Hokkaido, Japan (Fig. 1).

A segmentation model of the large interplate earthquakes near the junction of the Kuril Trench and the Japan Trench was proposed by Utsu (1972) and adopted by the Japanese government for the evaluation of the long-term earthquake potential (Fig. 1). In the Shikotan-oki segment, the 1969 $M_{\mathrm{w}}=8.2$ Shikotan-oki earthquake ruptured the plate interface. The October 4, $1994 M_{\mathrm{w}}=8.3$ earthquake occurred in this region, but it was an intraslab earthquake (Ozawa, 1996). The Nemuro-oki segment was ruptured by the $1894 M_{\mathrm{w}}=8.3$ Nemuro-oki and the $1973 M_{\mathrm{w}}=7.8$ earthquakes (Tanioka et al., 2007). The $1952 M=8.2$ Tokachi-oki and $2003 M_{\mathrm{w}}=8.0$ earthquakes ruptured the Tokachi-oki segment. The slip distribution of these earthquakes was considered to be similar in the area west of the Kushiro submarine canyon (Yamanaka and Kikuchi, 2004). Tsunami studies have suggested that the area east of the Kushiro submarine canyon was ruptured by the 1952 earthquake and not by the 2003 earthquake (Hirata et al., 2003; Satake et al., 2006). The $1994 M_{\mathrm{w}}=7.7$ Sanriku-

Copyright (c) The Society of Geomagnetism and Earth, Planetary and Space Sciences (SGEPSS); The Seismological Society of Japan; The Volcanological Society of Japan; The Geodetic Society of Japan; The Japanese Society for Planetary Sciences; TERRAPUB. oki (Sanriku-haruka-oki) earthquake ruptured the southern part of the source area of the $1968 M_{\mathrm{w}}=8.3$ Sanriku-oki (Tokachi-oki) earthquake, in the northern Sanriku-oki segment (Nagai et al., 2001). In addition to these $M \sim 8$ historical earthquakes, geological studies of tsunami deposits along the southern coast of Hokkaido suggest that a huge earthquake with $M>8.5$ ruptured both the Tokachi-oki and Nemuro-oki segments in the 17th century (Nanayama et al., 2003; Satake et al., 2008).

The 1973 Nemuro-oki earthquake has been studied by various researchers. Shimazaki (1974) constructed a rectangular fault model of this earthquake using teleseismic data and local leveling data. Tada (1974) also built a rectangular fault model using local vertical displacements measured by leveling and tide-gauges. Their results show that the focal mechanism of the earthquake was low-angle thrust faulting, which is typical for an interplate earthquake on the subducting plate. Namegaya and Tsuji (2005) proposed a fault model similar to that of Tada (1974), based on tsunami waveform data. Kikuchi and Fukao (1987) and Yamanaka (2006) performed waveform inversion on teleseismic seismographs to estimate the source process and slip distribution of the 1973 Nemuro-oki earthquake. Their results showed that the rupture propagated up-dip, that is, to the south-southeast. The moment magnitude of the 1973 Nemuro-oki earthquake was estimated to be 7.8-7.9 in these studies.

There is room to improve on the results of the previous studies that used the geodetic data of the Nemurooki earthquake. The first method is by using horizontal deformation. Only the vertical displacements observed by leveling and tide-gauge measurements have been used. 


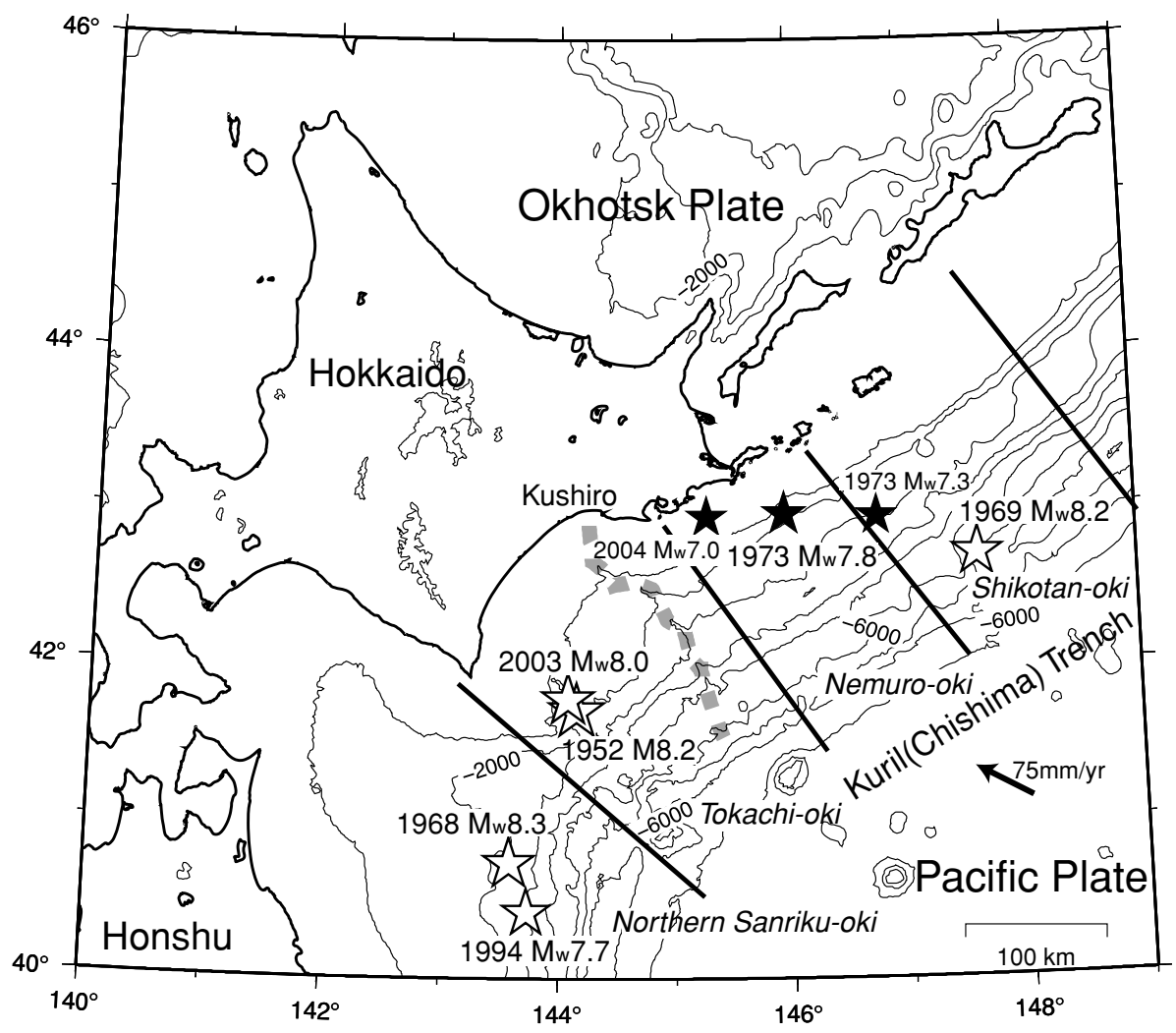

Fig. 1. Geographic map of the studied area. The epicenters of large interplate earthquakes are represented by stars. The epicenters of the 1973 Nemuro-oki earthquake $\left(M_{\mathrm{w}} 7.8\right)$, its largest aftershock $\left(M_{\mathrm{w}} 7.3\right)$, and the 2004 Kushiro-oki earthquake $\left(M_{\mathrm{w}} 7.0\right)$ are represented by solid stars. An arrow indicates the relative plate motion between the Pacific and Okhotsk plates (Sella et al., 2002). Four regions (i.e., Northern Sanriku-oki, Tokachi-oki, Nemuro-oki, and Shikotan-oki) are the segments of the source areas of the large earthquakes along the Kuril and Japan Trenches (Utsu, 1972). A thick broken line represents the Kushiro Submarine Canyon. The contour interval is $1000 \mathrm{~m}$.

Horizontal deformation can be derived from the triangulation/trilateration measurements that were performed in the 1960s and 1980s in Hokkaido. In addition, we found data for the baseline lengths measured using an Electric Distance Meter (EDM) near the source area. The second approach involves adjusting for interseismic deformation. The recurrence intervals for geodetic measurements, such as triangulation/trilateration and leveling, are generally larger than years or decades. The difference between two measurements includes coseismic deformation as well as postseismic and interseismic deformations. After the establishment of a nationwide GPS network (GEONET) in 1994, interseismic, coseismic, and postseismic deformations were continuously observed in Hokkaido (e.g., Sagiya et al., 2000; Miura et al., 2004; Ozawa et al., 2004; Baba et al., 2006; Suwa et al., 2006). We can use the average GPS velocity in the period when no large events occur for the adjustment of the interseismic deformation. The third method is estimating the slip distribution on the plate interface. Previous studies estimated simple models using a rectangular fault. Recently, the precise geometry of the plate interface southeast of Hokkaido has been proposed (Katsumata et al., 2003; Nakanishi et al., 2004). These models can be used to estimate the coseismic slip distribution on the plate interface. Compared with the teleseismic data, the local geodetic data have the advantage of better resolution for the absolute location of the slip distribution of the earthquake.

In this study, we first examined the geodetic data, in- cluding leveling, triangulation/trilateration, and repeated distance measurements, and adjusted these data for interseismic deformation in order to clarify the horizontal and vertical deformations associated with the 1973 Nemurooki earthquake. We then estimated the slip distribution of the Nemuro-oki earthquake using the adjusted geodetic data. We also estimated the slip distribution of the 2004 $M_{\mathrm{w}}=7.0$ Kushiro-oki earthquake that occurred near the source area of the Nemuro-oki earthquake using coseismic GPS displacements. Finally, we examined a possible afterslip model and made a comparison of the slip distribution of the Tokachi-oki earthquake, the Nemuro-oki earthquake, and the 2004 Kushiro-oki earthquakes.

\section{Geodetic Data}

The geodetic data used consisted of leveling and triangulation/trilateration data obtained during two measurement periods before and after the 1973 Nemuro-oki earthquake. We also used baseline measurement data acquired from EDM and vertical displacement at tide-gauge stations. The Geographical Survey Institute (GSI) has surveyed the national geodetic networks, which consist of horizontal control points and leveling benchmarks along principal roads, several times over the past $\sim 120$ years (Fig. 2(a) and (b)). Because these surveys span relatively long time intervals of up to 20 years, the geodetic data must include significant interseismic deformation. We applied corrections using the interseismic deformation observed at continuous 
(a)

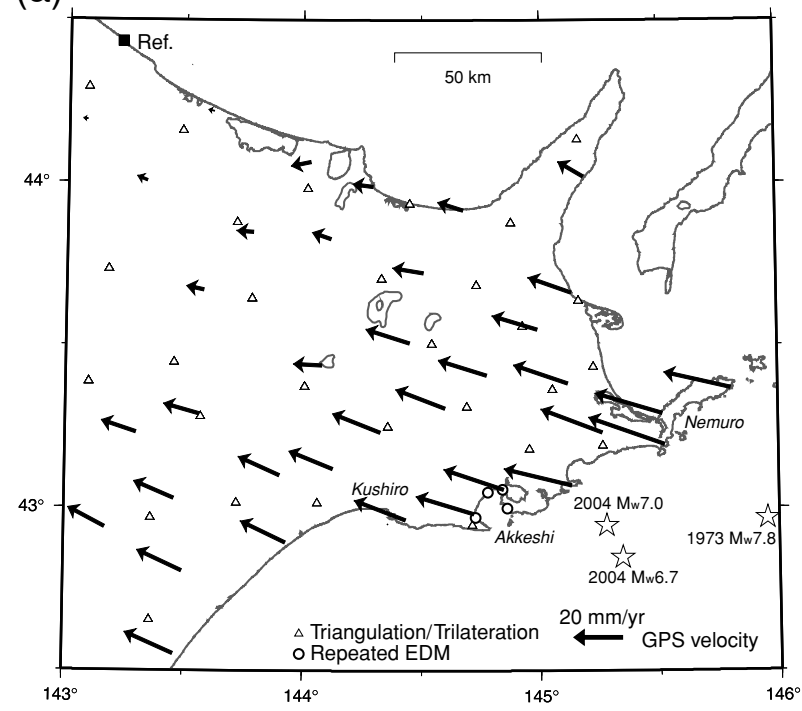

(b)

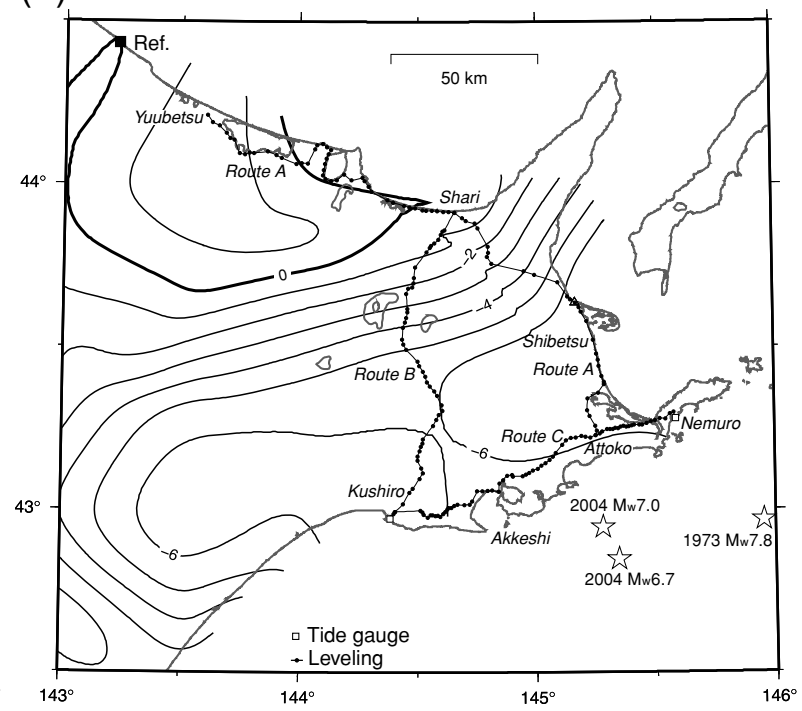

Fig. 2. Geodetic networks used in this study. (a) Sites for horizontal displacements. The triangles and circles are horizontal control points for triangulation and trilateration and stations for the repeated EDM measurements across Akkeshi Bay, respectively. Arrows represent the horizontal velocity vectors at continuous GPS stations during 1999-2003. (b) Sites for vertical displacements. The leveling routes are represented by lines with small circles. The squares are tide gauge stations. Contour lines with an interval of $1 \mathrm{~mm} / \mathrm{yr}$ represent the vertical velocity interpolated from the measurements at GPS stations during 1999-2003.

GPS (GEONET) stations. We assumed that the GPS velocity in the period from April 1999 to March 2003 was an average interseismic deformation. The small coseismic displacement associated with the January $28,2000 M_{\mathrm{w}}=6.8$ Nemuro-oki earthquake was removed to estimate the GPS velocity. The interseismic velocities at the control points and leveling benchmarks were interpolated from the GPS velocity using the method of Shen et al. (1996). We used $25 \mathrm{~km}$ for the Distance Decay Constant controlling the spatial smoothness for interpolation. The horizontal velocities at the GPS stations and the interpolated vertical velocities are plotted in Fig. 2(a) and (b), respectively. The horizontal movement was roughly parallel to the convergent movement between the subducting Pacific plate and the overriding Okhotsk plate. Both this movement and the subsidence along the Pacific coast suggest the presence of strong coupling on the plate boundary.

The large earthquakes that occur along the Kuril and Japan trenches are usually accompanied by significant postseismic deformations (e.g., Heki et al., 1997; Ozawa et al., 2004). The postseismic deformation of the 1973 Nemurooki earthquake was observed by leveling and tide-gauge measurements and was explained by afterslip on the downdip extension of the coseismic fault (Kasahara and Kato, 1980). However, it is very difficult to distinguish between coseismic and postseismic deformation in the geodetic data because most of the geodetic surveys were conducted a few years after the earthquake. Therefore, the "coseismic" deformation and slip model in this study include postseismic deformation and afterslip, respectively.

\subsection{Leveling and tide-gauge data}

The first-order leveling routes in Japan are surveyed by GSI roughly every 10 years. There are three routes near the epicenter of the 1973 Nemuro-oki earthquake (Fig. 2(b)). Route A runs from Yuubetsu to Attoko via Shari and Shi- betsu. Route B runs from Shari to Kushiro and Route C runs from Nemuro to Kushiro via Attoko and Akkeshi. Measurement errors for leveling (section heights between benchmarks) accumulate with the square root of distance, expressed as $\alpha \sqrt{L}$ where $L$ (in kilometers) is the distance between leveling benchmarks and $\alpha$ (in $\mathrm{mm} / \sqrt{\mathrm{km}}$ ) is a constant. These routes were leveled for 1969-1972, before the earthquake. Postseismic measurements were conducted from 1974 to 1978 . Because it covers Route C and part of Route A, we deal with the data collected by another postseismic campaign that took place from June to August 1973, not in this section, but in Section 4.3, during the discussion of early postseismic deformation. We applied corrections using the GPS velocity to remove interseismic deformation. The original and corrected displacements along the leveling routes are plotted in Fig. 3.

The coseismic deformation along Route $\mathrm{C}$ is the clearest among the three routes. The relative subsidence near Attoko amounts to $\sim 110 \mathrm{~mm}$. This subsidence is also found along Route A. Although the interseismic deformation before the correction shows a broad pattern along Routes A and B, the general pattern of the observed subsidence near Attoko did not change after the interseismic correction. For the tidegauge data, we used the monthly vertical displacement analyzed by the Geographical Survey Institute (2008) to estimate the vertical displacement in Kushiro and Nemuro (Hanasaki) along the Pacific coast (Fig. 2(b)). These data were derived after correcting for common noises in the monthly sea levels at the tide-gauge stations (Kato and Tsumura, 1979). These stations are located at the end points of leveling Route C (Fig. 3(c)). After the corrections for interseismic deformation and common noise were made, the coseismic displacement was calculated from the difference in the annual averages between 1972 and 1975. The coseismic subsidences in Kushiro and Nemuro (Hanasaki) 

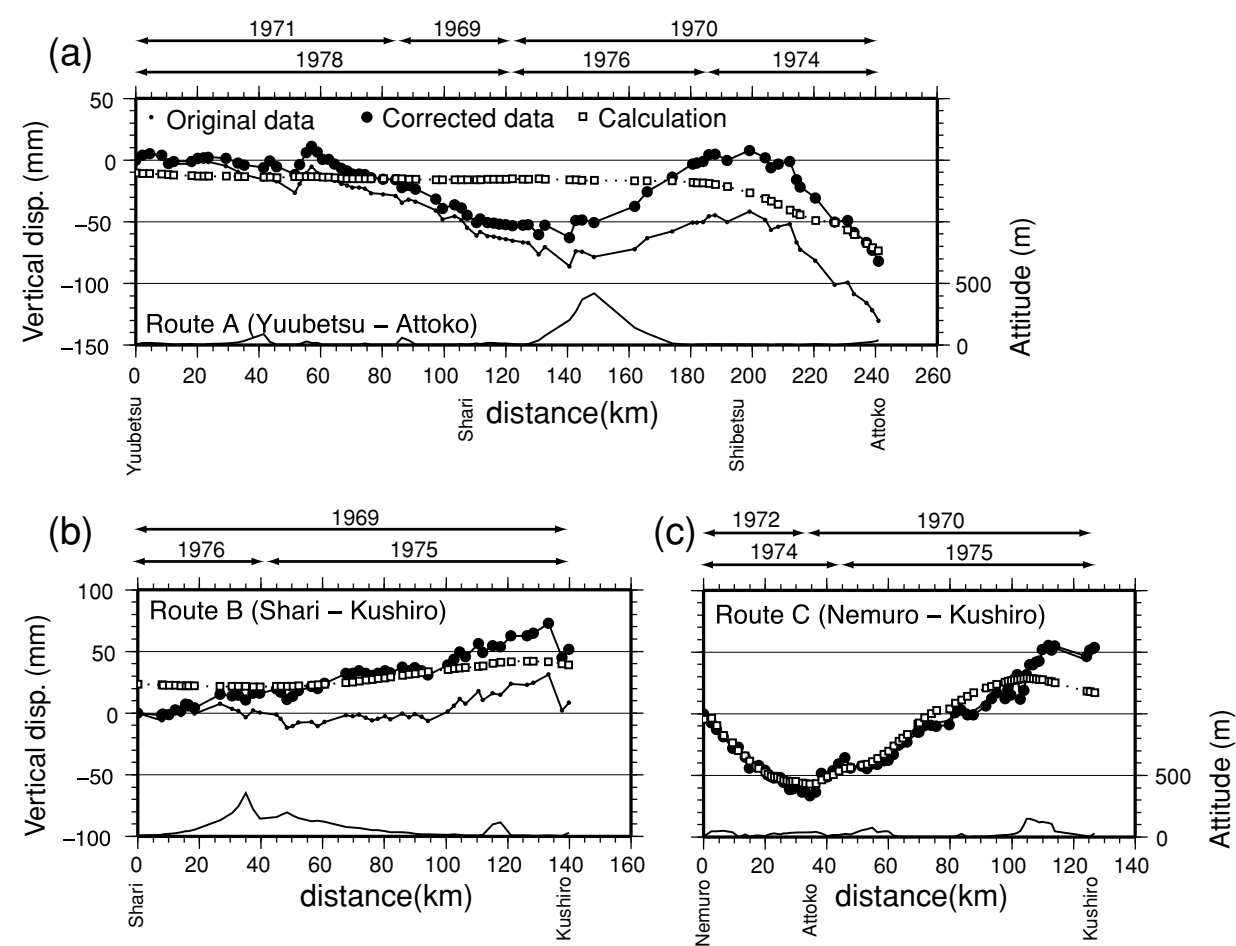

Fig. 3. Vertical displacements along leveling routes, which are associated with the 1973 Nemuro-oki earthquake. The small circles, large circles, and squares represent the observed data, data corrected for interseismic deformation, and data predicted by the fault model, respectively. The lines at the bottom represent the altitude along the routes. The four-digit numbers are the years of the preseismic and postseismic measurements. (a) Route A from Yuubetsu to Attoko. (b) Route B from Shari to Kushiro. (c) Route C from Nemuro to Kushiro.

(a)

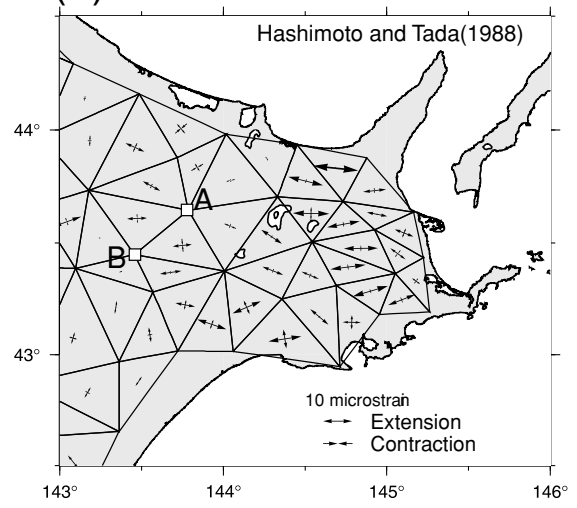

(b)

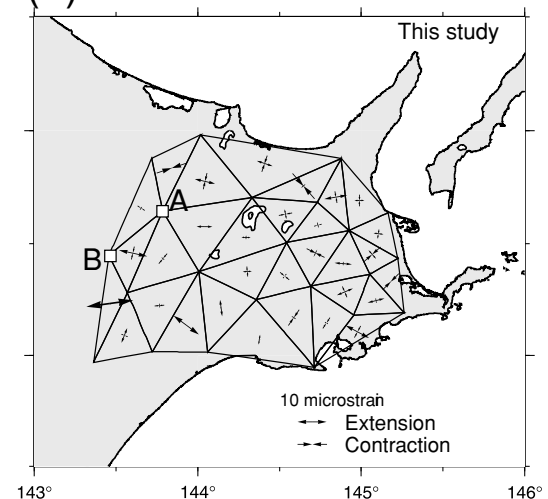

(c)

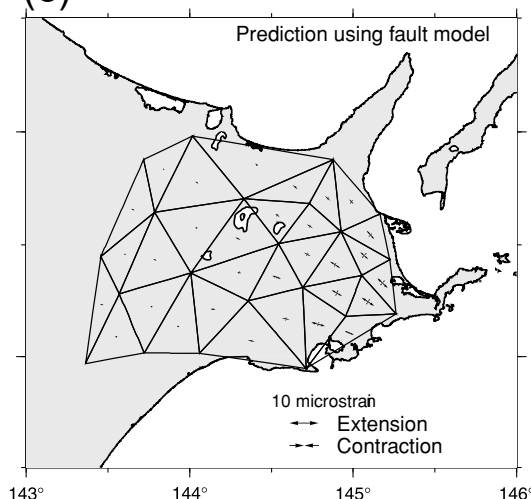

Fig. 4. Strain changes in the triangulation/trilateration network associated with the 1973 Nemuro-oki earthquake. (a) Strain change after the network adjustment by Hashimoto and Tada (1988). The preseismic and postseismic measurements were conducted by triangulation during 1964-1967 and by trilateration during 1982-1984, respectively. The deformation predicted by interseismic velocity models and the 1969 Shikotan-oki earthquake was removed. Points A and B represent control points for the coordinates assumed in the strategy of our network adjustment. (b) Strain change after the network adjustment of this study. The other conditions are the same as (a). (c) Strain change was predicted using the preferred fault model of the 1973 Nemuro-oki earthquake.

amounted to 1.6 and $4.9 \mathrm{~cm}$, respectively. The relative subsidence in Nemuro was quantitatively concordant with the leveling data.

\subsection{Triangulation/Trilateration data}

The 1973 Nemuro-oki earthquake occurred during the period of transitioning from the use of triangulation to trilateration to measure the horizontal locations of control points, i.e., survey markers. The first-order control points for triangulation and trilateration are located all over Japan, with an average spacing of $25 \mathrm{~km}$. A preseismic triangulation campaign for measuring the angles between the control points was conducted from 1964 to 1967 . A postseismic trilateration campaign for measuring the distance between control points was conducted from 1982 to 1984 . Because the measured quantities were different between the preseismic and postseismic surveys, we used the differences in the horizontal coordinates of the control points after network adjustment to estimate the coseismic displacement.

Hashimoto and Tada (1988) estimated the horizontal displacement and strain in Hokkaido based on the network adjustment of the data described above. Their results showed that the extension in the east-west direction reaches $13 \mathrm{mi}$ - 
(a)

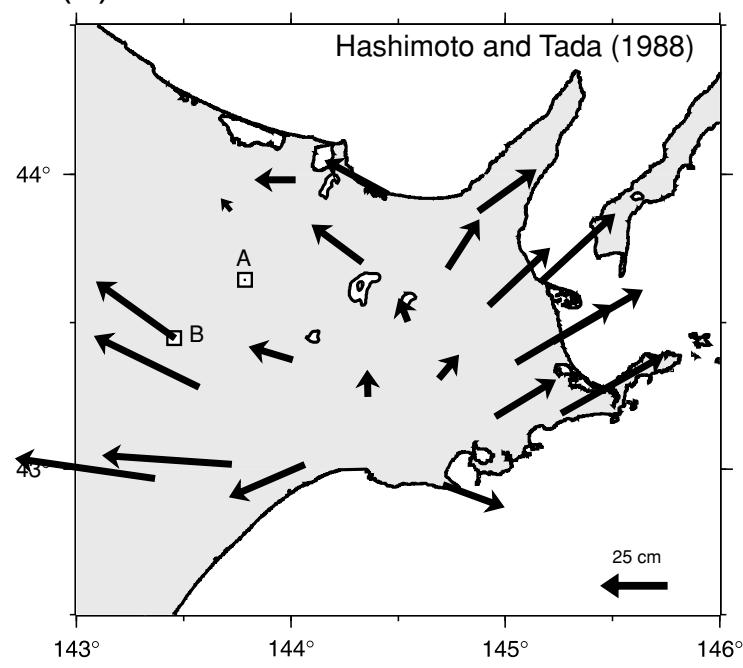

(b)

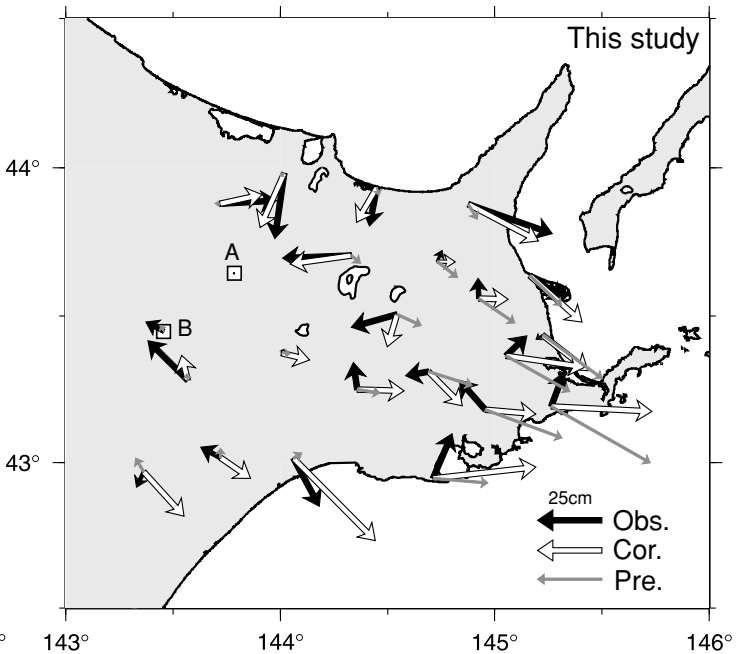

Fig. 5. Horizontal displacement vectors at control points after the network adjustment measured by triangulation and trilateration. (a) Displacements was calculated from a network adjustment using the strategy of Hashimoto and Tada (1988). (b) Displacements from a network adjustment using the strategy of this study (see text). The observed vectors denoted as black arrows are the result of the network adjustment. The corrected vectors shown by white arrows represent the displacement after subtracting the interseismic deformation and the coseismic deformation of the 1969 Shikotan-oki earthquake. The vectors shown by thin gray arrows represent the displacement predicted by the preferred fault model of this study.

crostrain in the easternmost part of Hokkaido. We applied the interseismic deformation correction (Fig. 4(a)) and found no change in the strain pattern. The direction of the extension was roughly concordant with the prediction of the 1973 Nemuro-oki earthquake, but its amount was too large for an $M_{\mathrm{w}}=7.8$ earthquake. In addition, both the original and corrected strain showed that a 10-20 microstrain was widely distributed in the northern and central parts of Hokkaido, where no large earthquakes occurred, which seems to be extremely large and unreasonable for the period of 1964-1967 to 1982-1984. Hashimoto and Tada (1988) pointed out the possibility that the estimated strain included scale errors for the station coordinates from triangulation. Therefore, we re-calculated the network adjustment for the triangulation data, with an additional constraint. Because the displacement is more sensitive than strain in representing deformation, we explain the network adjustment strategy in the form of displacement.

Figure 5(a) shows displacement vectors with respect to point A for the results of Hashimoto and Tada (1988). An extension in the east-west direction is dominant over the region. The neighboring point $\mathrm{B}$ shows a northwestward movement of $\sim 35 \mathrm{~cm}$. This movement is much faster than the interseismic GPS velocity during 1999-2003 (see Fig. 2(a)). The fault model for the two large earthquakes that occurred between two geodetic campaigns, that is, the 1969 Shikotan-oki and the 1973 Nemuro-oki earthquakes (Shimazaki, 1974; Fukao and Furumoto, 1975), predicted a relative displacement of less than $2 \mathrm{~cm}$ between points $A$ and B. Under the assumption that the rate of interseismic deformation does not change with time (e.g., Sagiya and Thatcher, 1999), the displacement at point B can be calculated to be $6.3 \mathrm{~cm}$ toward the west-northwest with respect to point A. This displacement is derived from the sum of the interseismic GPS velocity and the predicted coseismic displacement for the 1969 and 1973 earthquakes. With the constraint of site coordinates to fit the predicted displacement at points $\mathrm{A}$ and $\mathrm{B}$, we applied a network adjustment to the triangulation data using the source code of Komaki (1993). The standard deviation of the angle misfit per unit weight increased by $6 \%$ with the additional constraint in the network adjustment. The adjusted displacement is denoted as black arrows in Fig. 5(b). This displacement is relatively small and does not show a systematic pattern for the deformation. We applied the correction to the adjusted displacement by subtracting the interseismic displacement and the coseismic displacement of the 1969 earthquake. The corrected displacement showed eastward movements in the easternmost part of Hokkaido, which were qualitatively concordant with the displacement predicted for the Nemuro-oki earthquake. The corrected strain (Fig. 4(b)) was smaller than that of Hashimoto and Tada (Fig. 4(a)) but showed a rather random pattern.

\subsection{Distance data by EDM}

GSI was used to measure the distances for six baselines between four markers in Akkeshi Bay facing the Pacific (Figs. 2(a) and 6) ten times for the period of 1971 to 1993 . These measurements were obtained with EDM, except for the last one, which used GPS. The coseismic change in a baseline length is defined as the difference between the average of two preseismic measurements acquired in July 1971 and July 1972 and one postseismic measurement acquired in September 1974. We applied the interseismic deformation correction, which was less than $3 \mathrm{~mm}$ for 2.5 years. The coseismic changes showed extensions in most baselines (Fig. 6). In particular, they were distinct in east-west oriented baselines. The distance changes in $\mathrm{AK} 4-\mathrm{AK} 2$ and $\mathrm{AK} 3-\mathrm{AK} 2$ were converted to +5.9 and +4.6 microstrain, respectively (a positive value represents an extension). Although these data have never been used for the modeling of the 1973 Nemuro-oki earthquake, they are conducive to estimating the slip distribution because the 


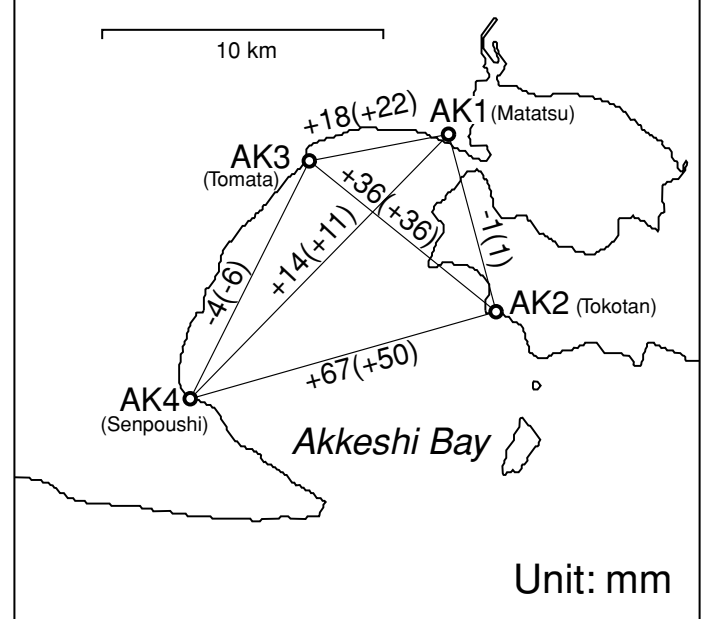

Fig. 6. Distance changes associated with the 1973 Nemuro-oki earthquake across Akkeshi Bay. The numbers are the amounts of change (in $\mathrm{mm}$ ). The numbers in parentheses show the values calculated by the preferred model.

baselines in Akkeshi Bay are located near the northwestern edge of the source area of the Nemuro-oki earthquake.

\section{Inversion Analysis}

\subsection{Inversion procedure}

The 1973 Nemuro-oki earthquake occurred on the plate interface between the subducting Pacific plate and the overriding Okhotsk plate. The geometry of the plate interface was studied using microseismicity (Katsumata et al., 2003) and a wide-angle ocean bottom seismographic survey (Nakanishi et al., 2004). We used the isodepth model of the plate interface (Fig. 7; Headquarters for Earthquake Research Promotion, 2004) developed in previous studies. We assumed a model region that covered the aftershock area of the 1973 earthquake. We also assumed western and northern edges for the model region that were wider than the aftershock area in order to investigate the extent of coseismic and postseismic slip. For the eastern and southern edges, we assumed a model region limited to the aftershock area and the previous model based on tsunami data (Namegaya and Tsuji, 2005) because the geodetic data used in this study did not have sufficient resolution to specify offshore slips (e.g., Sagiya and Thatcher, 1999).

The geometry of the plate interface was approximated by a $10 \times 10$ grid of rectangular faults (Fig. 7). The length of each fault was $20 \mathrm{~km}$, but the width varied from $20 \mathrm{~km}$ to $34 \mathrm{~km}$, depending on the fault dip, because we assumed that they were $20 \times 20 \mathrm{~km}$ on the projection to the Earth surface. We calculated synthetic surface displacements using the formulation of Okada (1985), assuming a homogeneous elastic half-space. Models of global plate motion (e.g., DeMets et al., 1994; Sella et al., 2002) have predicted that the direction of relative plate motion at $43^{\circ} \mathrm{N}$ and $145^{\circ} \mathrm{E}$ ranges from $292.9^{\circ}$ to $297.2^{\circ}$. The slip angle was fixed at $120-145^{\circ}$ based on the fault strike, which was the opposite of the adopted azimuth $\left(295^{\circ}\right)$ for the relative plate motion. We applied a constraint on the smoothness of the slip distribution by minimizing both the data misfit and the second differences of slip amount for neighboring faults along

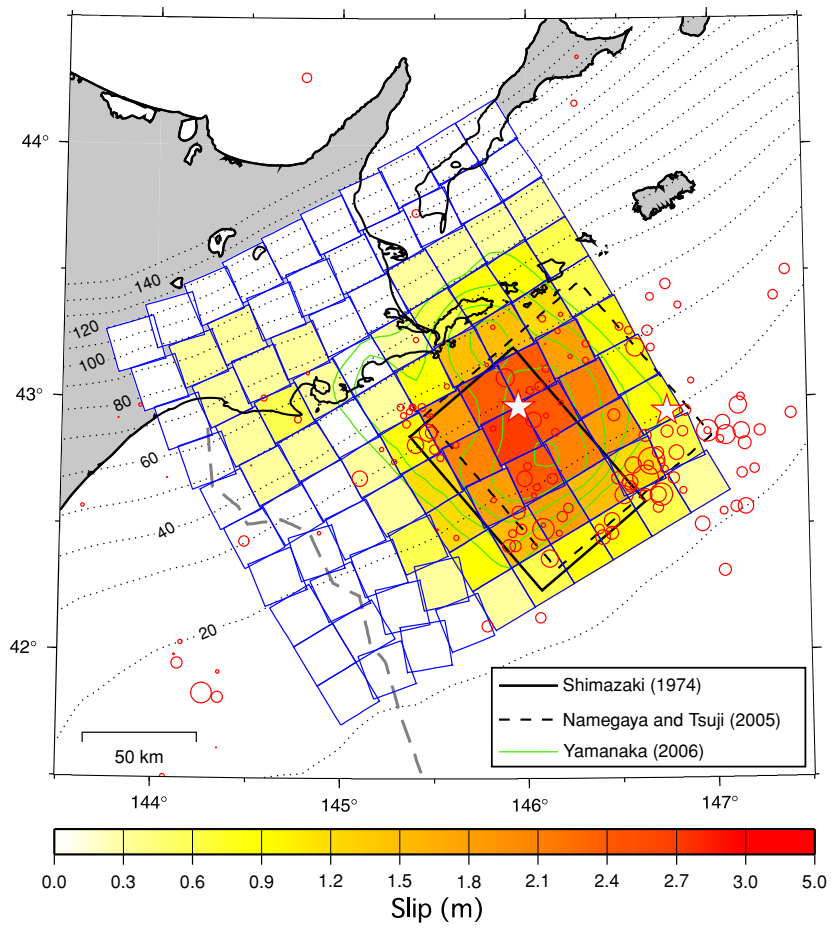

Fig. 7. Slip distribution for the 1973 Nemuro-oki earthquake. The stars represent the epicenters of the mainshock and the largest aftershock. The red circles are the epicenters of earthquakes with magnitudes $\geq 4$ from July 13, 1973 to December 31, 1974. The dotted lines represent the isodepth of the plate interface at intervals of $10 \mathrm{~km}$. The thick broken line represents the Kushiro Submarine Canyon. The fault models of Shimazaki (1974), Namegaya and Tsuji (2005), and Yamanaka (2006) are plotted. Yamanaka's model uses 0.5 -m contour intervals.

the strike and dip directions, respectively. The smoothness of the slip distribution can be written as $\sum_{n} \sum_{m}\left(\left(2 s_{n, m}-\right.\right.$ $\left.\left.s_{n-1, m}-s_{n+1, m}\right)+\left(2 s_{n, m}-s_{n, m-1}-s_{n, m+1}\right)\right)^{2}$, where $s_{n, m}$ is the slip amount on the $n$ - and $m$-th patches along the strike and dip direction. We also assumed small slip at the edge of the model region and non-negative slip in order to obtain stable and reasonable results for offshore slip. The constraint for small slip at the edge is realized by assuming additional fault patches whose slip amount is zero outside the model region. These additional faults are used only for calculating the smoothness of slip distribution and are not suitable for calculating the surface displacements. The hyperparameter used to control the strength of the constraint was objectively determined by minimizing Akaike's Bayesian Information Criterion (ABIC) (Akaike, 1980).

Because we used data observed by different techniques, we had to weigh the data for the inversion analysis. For the leveling data, we used the relative displacement in the section between two adjacent benchmarks. We assigned uncertainties of 0.9 to $2.1 \mathrm{~mm}$, corresponding to the measurement errors for the first-order leveling. The errors in section heights are uncorrelated. For the triangulation and trilateration data, we used three components of strain (i.e., normal strain in the eastern and northern directions and shear strain) in Delaunay triangles whose apexes were control points. The reason why we used strains instead of displacements is that the strains are free from a reference point for the displacements. If we use the displacements relative to 
the reference point, systematic errors, including scale errors for the triangulation data, may accumulate for the displacements far from the reference point. The uncertainties were assumed to be one microstrain, based on a rough estimate of the measurement errors for the triangulation and trilateration data (Hashimoto and Tada, 1988). We assumed uncertainties of 1 and $5 \mathrm{~mm}$ for the EDM and tide-gauge data, respectively. The total number of geodetic data points used was 299.

\subsection{Results}

The distribution of the estimated coseismic slip for the 1973 Nemuro-oki earthquake was characterized by a simple symmetric pattern, in which the peak slip was located near the epicenter of the mainshock (Fig. 7). The maximum slip was estimated to be $2.7 \mathrm{~m}$. The second slip peak was located near Kushiro, in the northwestern part of the model region. Our interpretation is that this second peak was not directly ruptured by the 1973 Nemuro-oki earthquake, because patches of small slip $(\leq 0.21 \mathrm{~m})$ can be recognized as a slip gap dividing the second peak from the first one. The total moment in the model region was $1.3 \times 10^{21} \mathrm{~N} \cdot \mathrm{m}$ $\left(M_{\mathrm{w}} 8.0\right)$, assuming a rigidity of $40 \mathrm{GPa}$. If we exclude the second peak, the moment is $1.2 \times 10^{21} \mathrm{~N} \cdot \mathrm{m}\left(M_{\mathrm{w}} 8.0\right)$. This seismic moment is roughly concordant with that of the previous studies $\left(0.7-1.0 \times 10^{21} \mathrm{~N} \cdot \mathrm{m}\right)$ because it depends on the assumed model region. If we use another model region without the southernmost patches of the present model, the estimated moment decreases by $30 \%$. Although our estimated moment has uncertainties, it is certain that the seismic moment of the 1973 Nemuro-oki earthquake is roughly identical to that of the $2003 M_{\mathrm{w}}=8.0$ Tokachi-oki earthquake, which ruptured the adjacent area of the plate interface to the west. The estimated slip error ranged between 4 and $8 \mathrm{~cm}$. It was necessary to ensure that the slip in the offshore (southern) and deep (northern) region was controlled by the smoothness constraint, whereas the slip near the $\mathrm{Pa}$ cific coast was relatively resolved by the geodetic data.

Our preferred model reproduced the leveling (Fig. 3) and EDM (Fig. 6) data well, but the triangulation/trilateration (Fig. 4) and tide-gauge data poorly. The relative subsidence at a distance of approximately $35 \mathrm{~km}$ on leveling Route $\mathrm{C}$ was reproduced very well (Fig. 3(c)). The broad subsidence at a distance of approximately $130 \mathrm{~km}$ on Route A could not be explained by the preferred model. No slip in the model region could explain this subsidence because the subsided area is far from the model region on the plate interface. This indicates that another mechanism is necessary to explain all of the observed vertical displacement. In contrast, the large misfit of the triangulation/trilateration data may be attributed to large measurement errors. Although the preferred model predicted a simple pattern of extension toward the epicenter, the observed strain did not show such a systematic pattern (Fig. 4). In the form of the displacements instead of the strains used in the inversion (Fig. 5), our preferred model roughly reproduces the eastward displacements represented by open arrows in a southeastern part of the area with large misfits west of $144.5^{\circ} \mathrm{E}$. The average for the triangulation measurement errors was about 1.6 arcsec by calculating the mis-closure of the 12 triangles used in this study. This value is considerably worse than the $0.7-1.2$ arcsec in the Shikoku region (Sagiya and Thatcher, 1999) and the 0.83 arcsec in the Kanto region (Nyst et al., 2006). Therefore, we concluded that the triangulation data used did not explain the deformation of the 1973 Nemuro-oki earthquake well. In contrast, the EDM data from Akkeshi Bay was well reproduced by the preferred model (Fig. 6). The predicted extension in the WNW-ESE direction around Akkeshi Bay (Fig. 4(c)) was in good agreement with the observed distance change. While the vertical displacements at the Kushiro and Nemuro (Hanasaki) tide-gauge stations were -1.6 and $-4.9 \mathrm{~cm}$, respectively, they were predicted to be 0.1 and $-2.5 \mathrm{~cm}$.

\section{Discussion}

4.1 Slip distribution of the 1973 Nemuro-oki earthquake and its relation to the Tokachi-oki earthquake

Comparing the estimated slip distribution and the epicenters of the aftershocks that occurred in 1973 (Fig. 7), we found that most of the aftershocks occurred in the region where the slip was estimated to be 1-2 m, beyond the slip peak. A supplemental pattern between the large coseismic slip and aftershock results have often been observed in other interplate earthquakes (e.g., Yamanaka and Kikuchi, 2004). The slip estimated here was roughly concordant with that estimated by previous researchers (Shimazaki, 1974; Namegaya and Tsuji, 2005; Yamanaka, 2006). More precisely, our preferred model had slip that extended down to a depth of $90 \mathrm{~km}$, which was deeper than that of the previous models. This was partly because we used the smoothness constraint in the inversion analysis. However, it is reliable to say that a slip region reached the Pacific coast at a depth of around $60 \mathrm{~km}$ because the slip there was resolved by the leveling data on Routes A and C. Because our data included postseismic deformation over a few years, the wider slip region of our model suggested that afterslip occurred in the deeper part of the plate interface, as discussed in Section 4.3 and also proposed by Kasahara and Kato (1980). Comparing the thermal model in this region (Nakanishi et al., 2004), the downdip limit of the co- and post-seismic slip (i.e., a depth of $90 \mathrm{~km}$ ) corresponds to an isotherm of $350-400^{\circ} \mathrm{C}$ on the plate interface, which is the temperature of the transition zone from stick slip to stable sliding for crustal rocks (e.g., Oleskevich et al., 1999). It is significantly deeper than the intersection between the plate interface and the continental forearc Moho. We therefore inferred that the downdip limit of the co- and post-seismic slip was mainly controlled by temperature rather than by the continental Moho, which is concordant with the case of the Japan Trench, where interplate thrust earthquakes occurred down to a depth of $60 \mathrm{~km}$ (Seno, 2005) and afterslip propagated down to a depth of $80 \mathrm{~km}$ (Nishimura et al., 2004). This inference is supported by significant interplate coupling down to a depth of $100 \mathrm{~km}$ estimated from interseismic GPS velocity data from 1997-2001 (Suwa et al., 2006).

The western edge of the slip area was significantly east of the Kushiro Submarine Canyon, which is a little west of that estimated in previous models. It was concordant with the segment boundary for large earthquakes proposed by 


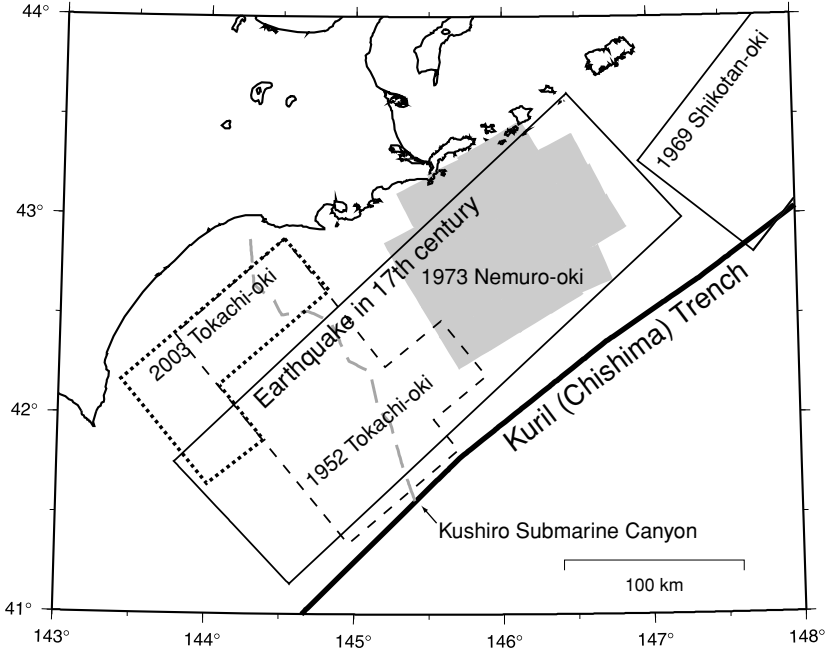

Fig. 8. Comparison of slip area of large interplate earthquakes along the southern part of the Kuril Trench. The slip area for the $1973 \mathrm{Ne}$ muro-oki earthquake represents the area where slip amount is estimated to be larger than $1 \mathrm{~m}$ in this study. The areas for the 1952 and 2003 Tokachi-oki earthquakes represent the area of more than $1 \mathrm{~m}$ of slip estimated by Satake et al. (2006) and Tanioka et al. (2004), respectively. The areas for the 1969 Shikotan-oki earthquake and the huge earthquakes in 17 th century represent rectangular faults estimated by Fukao and Furumoto (1975) and Satake et al. (2008).

Utsu (1972) (Fig. 1). Because the coseismic-slip area of the 2003 Tokachi-oki earthquake was west of the Kushiro Submarine Canyon (Yamanaka and Kikuchi, 2003; Tanioka et al., 2004; Miyazaki and Larson, 2008), there was a 50km-long gap between the 1973 Nemuro-oki and the 2003 Tokachi-oki earthquakes along the Kuril trench (Fig. 8). Large afterslip following the 2003 Tokachi-oki earthquake occurred in the gap near the Kushiro Submarine Canyon (e.g., Ozawa et al., 2004; Baba et al., 2006). In contrast, the slip area of the 1952 Tokachi-oki earthquake overlaps that of the 2003 earthquake and expands to the east. According to tsunami studies (Hirata et al., 2003; Satake et al., 2006), the largest slip occurred near the Kushiro Submarine Canyon and adjoining the estimated slip area of the 1973 Nemuro-oki earthquake. However, the eastern limit of the 1952 Tokachi-oki earthquake is still under debate because the seismic and geodetic data do not require the eastern part of the slip near the Kushiro Submarine Canyon (Yamanaka and Kikuchi, 2003; Nishimura, 2006). In addition, a huge earthquake with moment magnitudes of 8.5 ruptured a $300 \mathrm{~km}$-long region that included the Tokachioki and Nemuro-oki segments in the 17th century (Satake et al., 2008). These results suggest that the slip behavior on the plate interface near the Kushiro Submarine Canyon is variable between seismic and aseismic, presumably depending on the stress state and stiffness of an external force, which can be explained by numerical and laboratory experiment for frictional slip (e.g., Yoshida et al., 2004).

Because of the resolution of the data used, we cannot rule out the possibility that the slip of the 1973 Nemurooki earthquake expanded to the east and south. Thus, based on the results of our analysis, we are unable to discuss the spatial relationship between the coseismic slip of the 1973 Nemuro-oki and the 1969 Shikotan-oki earthquakes.

\subsection{Spatial relation with the 2004 Kushiro-oki earth- quake}

An $M_{\mathrm{w}}=7.0$ earthquake occurred near the northwestern edge of the 1973 Nemuro-oki earthquake on November 29, 2004 (Figs. 1 and 2$)$. The largest aftershock $\left(M_{\mathrm{w}} 6.7\right)$ followed 7 days later. These earthquakes are called the 2004 Kushiro-oki earthquakes. The aftershock distribution and focal mechanism estimated by seismic waveform inversion (Katsumata and Yamanaka, 2006) suggest that they were interplate earthquakes on the subducting Pacific plate. The magnitude of the Kushiro-oki earthquakes was smaller than that of the large interplate earthquakes, such as the 1973 Nemuro-oki, the 1969 Shikotan-oki, and the 1952 and 2003 Tokachi-oki earthquakes, by one order of magnitude. We estimated the slip distribution of these Kushiro-oki earthquakes and compared it with that of the Nemuro-oki earthquake.

Clear coseismic displacements for the mainshock and the largest aftershocks were observed by continuous GPS (GEONET). We defined the deformation associated with these earthquakes as the differences in the average daily coordinates between November 19-28 and December 1423, as shown in Fig. 9. This deformation includes the coseismic deformation of both earthquakes and the possibly early postseismic deformation. The deformation shows a characteristic spatial pattern, in which stations around Akkeshi Bay and Nemuro moved southeastward and northeastward, respectively. Using the same procedure as that for the Nemuro-oki earthquake, we inverted the observed displacement to estimate the slip distribution for the Kushirooki earthquakes. The results showed that the slip was limited to near the epicenters of the two earthquakes (Fig. 10). The maximum slip was $0.9 \mathrm{~m}$. The total moment was $5.9 \times 10^{19} \mathrm{~N} \cdot \mathrm{m}\left(M_{\mathrm{w}} 7.1\right)$, which is approximately equal to the sum $\left(5.3 \times 10^{19} \mathrm{~N} \cdot \mathrm{m}\right)$ of the two earthquakes estimated by the Global CMT Project.

A comparison between Figs. 7 and 9 shows that the slip area of the Kushiro-oki earthquakes was located just at the northwestern edge of that of the Nemuro-oki earthquake. Therefore, it is difficult to determine whether the slip area of the 1973 Nemuro-oki earthquake included that of the 2004 Kushiro-oki earthquake. We speculate that the asperity of the Kushiro-oki earthquakes was not ruptured by the Nemuro-oki earthquake, based on the following reasons. The amount of slip for the Nemuro-oki earthquake was $0.5 \mathrm{~m}$ in the patch where the slip of the Kushiro-oki earthquake was the largest. This is about half the slip of the Kushiro-oki earthquake. Second, there was a gap in the slip near this particular patch for the Nemuro-oki earthquake. We interpreted this gap to mean that the slip region of the Kushiro-oki earthquake played the role of a barrier and stopped the slip propagation during the Nemuro-oki earthquake.

There is an alternative interpretation of small slip for the Nemuro-oki earthquake in the slip area of the Kushiro-oki earthquake. An $M=7.2$ Kushiro-oki earthquake occurred on August 12, 1961. The largest aftershock ( $M$ 6.9) followed on November 15, 1961. The epicenters and magnitudes of these earthquakes occurring in 1961 are quite similar to those of the 2004 Kushiro-oki earthquakes, which 
(a)

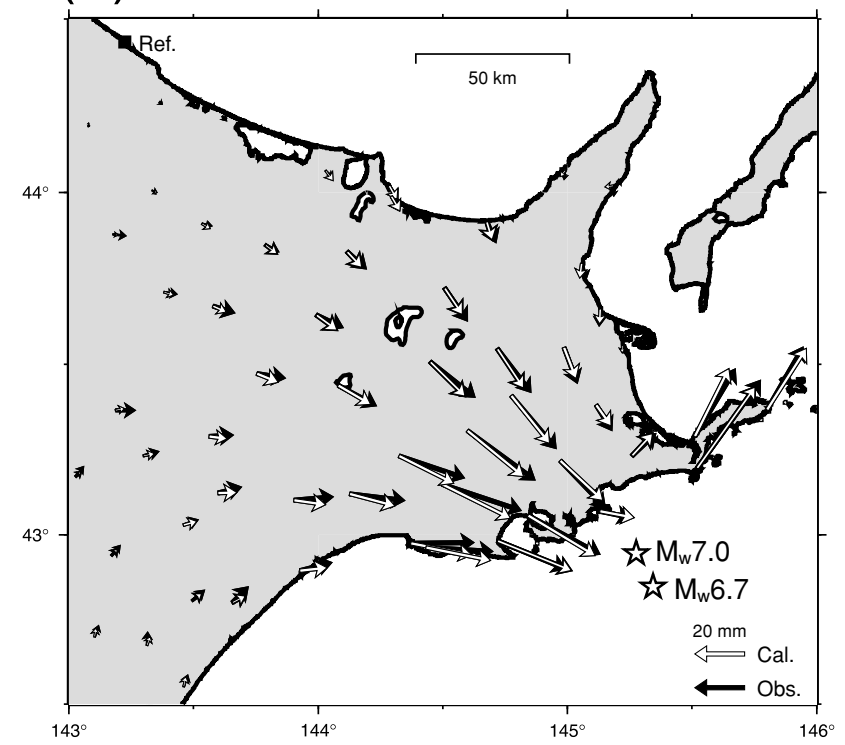

(b)

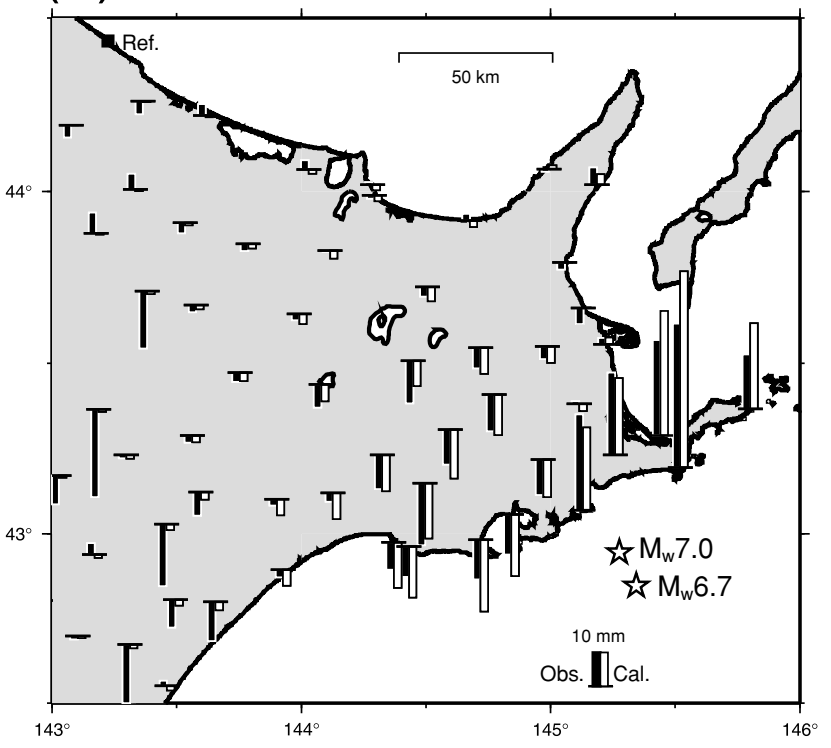

Fig. 9. Displacements at the continuous GPS stations associated with the $2004 M_{\mathrm{w}}=7.0$ and $M_{\mathrm{w}}=6.7$ Kushiro-oki earthquakes. The solid and open symbols represent the observed and calculated displacements, respectively. (a) Horizontal displacements. (b) Vertical displacements.

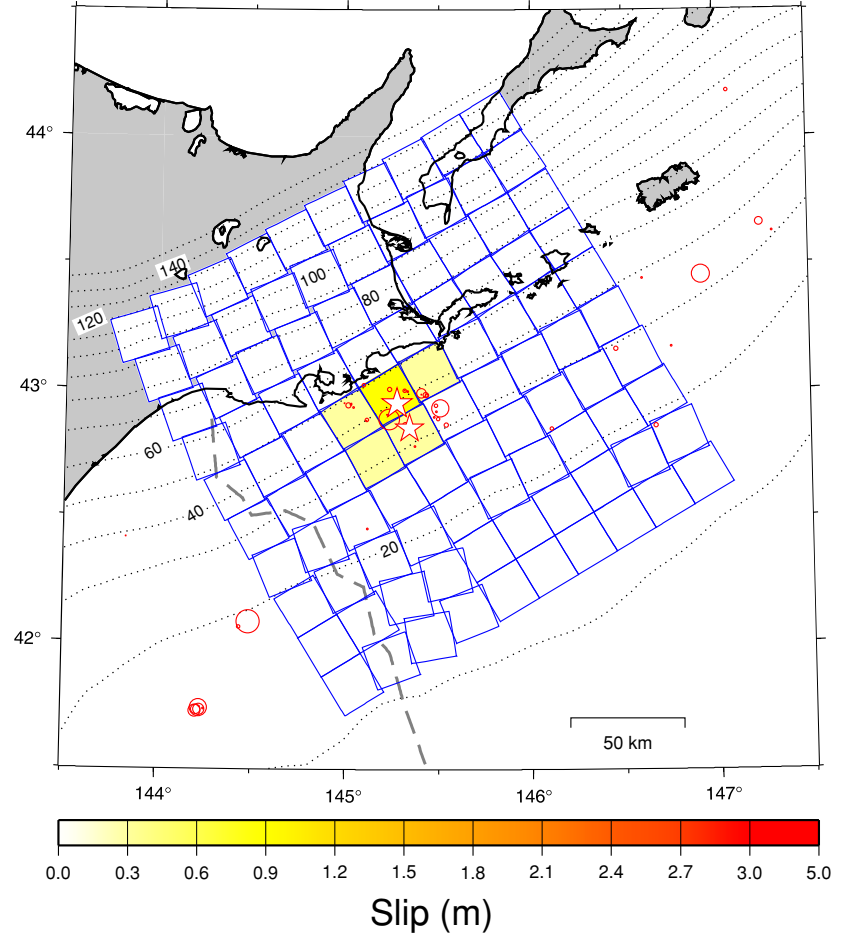

Fig. 10. Slip distribution for the $2004 M_{\mathrm{w}}=7.0$ and $M_{\mathrm{w}}=6.7$ Kushiro-oki earthquakes. The stars represent the epicenters of these earthquakes. The red circles are the epicenters of earthquakes with magnitudes $\geq 4$ in November and December 2004 .

suggests that the 1961 and 2004 earthquakes are recurrent events that ruptured the same area. If the 1961 earthquakes released the strain in the slip patches of the 2004 earthquakes, the strain had not accumulated for the period between 1961 and 1973. It, therefore, caused to any large degree a small slip during the 1973 Nemuro-oki earthquake.

\subsection{Afterslip model of the 1973 Nemuro-oki earth- quake}

Significant postseismic deformation associated with the 1973 Nemuro-oki earthquake was observed in the tidegauge data of Nemuro (Hanasaki) and in the leveling data. Kasahara and Kato (1980) concluded that the postseismic uplift was finished at the Hanasaki tide-gauge station in late 1975 and that it recovered to a preseismic subsidence rate of $\sim 10 \mathrm{~mm} / \mathrm{yr}$. However, long-term tide-gauge data, after common noise correction (Geographical Survey Institute, 2008), showed that Hanasaki did not subside for more than 10 years after the earthquake, but then started to subside at a rate of $10 \mathrm{~mm} / \mathrm{yr}$ in the late $1980 \mathrm{~s}$. Therefore, the postseismic deformation of the 1973 Nemuro-oki earthquake can be characterized by two temporal phases. The first phase of deformation was a short-term one that rapidly uplifted Nemuro (Hanasaki) until late 1975. The second phase was a long-term deformation that continued for more than a decade. We extracted the postseismic deformation from the leveling and tide-gauge data using the data measured just after the earthquake. Figure 11 shows the difference between the first leveling measurements taken from June 30 to August 4, 1973 and the second ones taken from July 1974 to September 1976, corresponding to the first phase of postseismic deformation. We also estimated vertical displacements of 6.0 and $-1.2 \mathrm{~cm} 2.5$ years after the earthquake in Nemuro (Hanasaki) and Kushiro, respectively. These values were calculated from the data of monthly vertical displacement at the tide-gauge stations (Geographical Survey Institute, 2008) after correcting for the interseismic displacement velocity.

Although both the afterslip on the fault and viscoelastic relaxation in the asthenosphere are important mechanisms to cause postseismic deformation, several examples of nearby interplate earthquakes, including the 1994 $M_{\mathrm{w}}=7.7$ Sanriku-oki and $2003 M_{\mathrm{w}}=8.0$ Tokachi-oki 

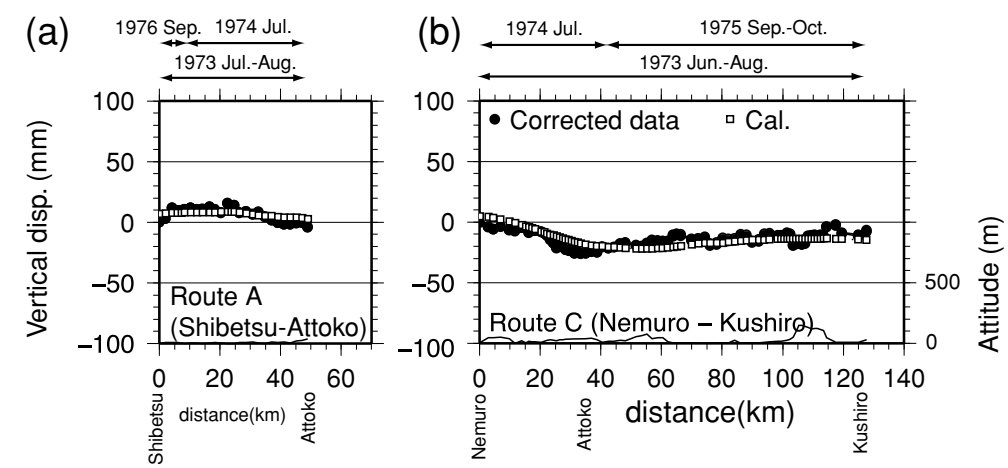

Fig. 11. Vertical displacements for the postseismic period of the 1973 Nemuro-oki earthquake. The periods for the two measurements are shown at the top of the graphs. (a) Southern part of Route A. (b) Route C.

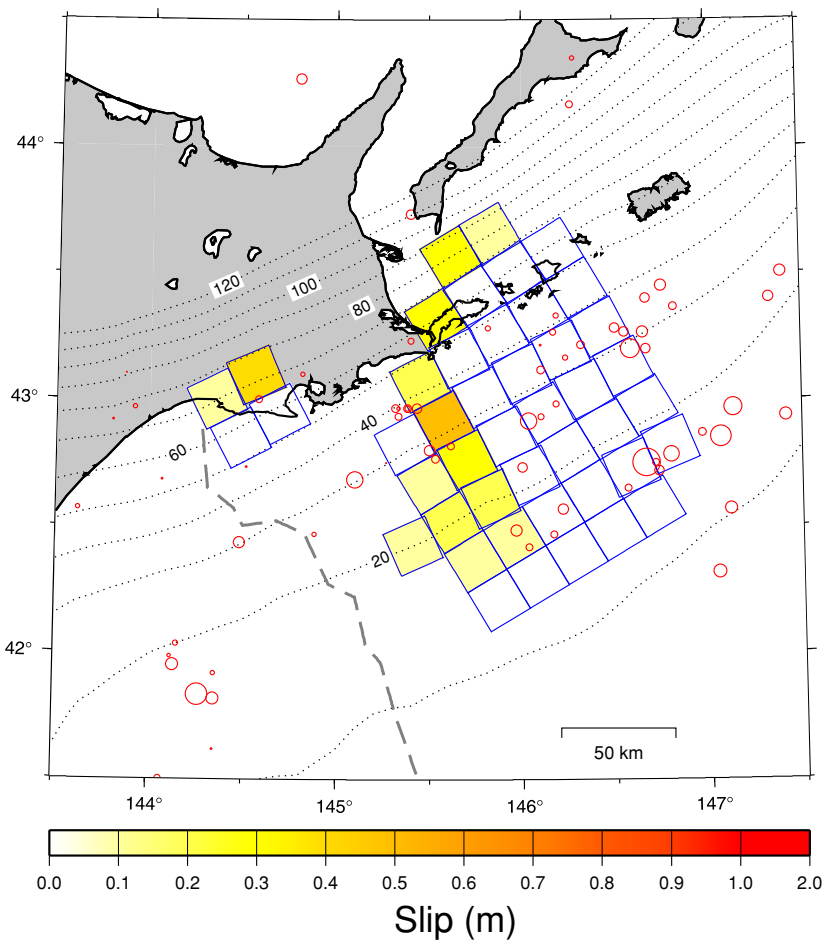

Fig. 12. Slip distribution for afterslip of the 1973 Nemuro-oki earthquake. The red circles represent the epicenters of earthquakes with magnitudes $\geq 4$ from August 1973 to December 1974. Note that the color scale is different from those of Figs. 7 and 10.

earthquakes (Heki et al., 1997; Nishimura et al., 2004; Baba et al., 2006), suggest that an early stage of postseismic deformation is dominantly caused by afterslip on the plate interface. Therefore, we assumed that the first type of postseismic deformation (Fig. 11) was caused by afterslip, and estimated the afterslip distribution. Although it was difficult to estimate the afterslip distribution objectively due to the limited data-set, we suggest a possible model to explain the observed data.

The data used to estimate the "coseismic slip" in Section 3 actually included both coseismic and postseismic deformation, because the postseismic measurements were made 1-11 years after the earthquake. Therefore, the "coseismic slip" shown in Fig. 7 includes afterslip. We only assumed patches where the "coseismic slip" was larger than
$0.5 \mathrm{~m}$ in the model region. The inversion procedure was the same as that described in Section 3, with two exceptions. We did not use the constraint of the slip vanishing at the edge of the model region, and we used a larger hyperparameter (i.e., smooth slip distribution) and not that optimized by ABIC. For no constraint of the slip at the edge, we assumed that the slip amount on the additional fault patches outside of the model region was the same to that on the adjacent edge patch instead of zero (see Section 3.1). The estimated afterslip distribution (Fig. 12) showed that an afterslip with a maximum slip of $0.6 \mathrm{~m}$ occurred at the western and northern edges of the coseismic slip and that little slip was estimated in the asperity and at the eastern and southern edges of the coseismic slip. The total moment of the afterslip was $6.9 \times 10^{19} \mathrm{~N} \cdot \mathrm{m}\left(M_{\mathrm{w}} 7.2\right)$, which was smaller than that of the coseismic slip by one order of magnitude. The moment and slip in the offshore region must have been underestimated due to the poor resolution using the vertical displacement data. However, we can at least conclude that an expansion of the afterslip toward the west and deep parts of the plate interface was resolved by the observed data. This suggests that the afterslip occurred mainly around the asperity, which was also observed in the 2003 Tokachi-oki earthquake (Baba et al., 2006).

\section{Conclusion}

We examined the geodetic data, including leveling, tidegauge, triangulation/trilateration, and repeated EDM data, to estimate the slip distribution of the 1973 Nemuro-oki earthquake. We estimated the fault model of the 2004 Kushiro-oki earthquake using GPS data. A possible afterslip model was suggested based on the leveling and tidegauge data. The results are summarized as follows:

(1) By the network adjustment of triangulation/trilateration data with two fixed stations, the strain and displacement from the period of 1964-1967 to that of 1982-1984 do not show a systematic pattern in eastern Hokkaido near the epicenter of the Nemuro-oki earthquake, whereas a previous study showed unnaturally large extensions in the east-west direction. The triangulation/trilateration data do not sufficiently constrain the fault model for the Nemuro-oki earthquake, due to a low signal-to-noise ratio. 
(2) The repeated EDM data clearly show coseismic changes in the baseline distances, which have never been used in previous studies. These contributed to an estimation of the northwestern edge of the slip area of the Nemuro-oki earthquake.

(3) The estimated moment magnitude $\left(M_{\mathrm{w}} 8.0\right)$ of the 1973 Nemuro-oki earthquake was the same size as the 2003 Tokachi-oki earthquake, which ruptured a neighboring region. The asperity of the Nemuro-oki earthquake, with a maximum slip of $2.7 \mathrm{~m}$, was located near the epicenter of the mainshock. Aftershocks actively occurred near the edge of the estimated slip region. The western edge of the coseismic slip was significantly east of the Kushiro Submarine Canyon. Therefore, there was a significant gap in the ruptured area between the Nemuro-oki and the 2003 Tokachioki earthquakes.

(4) The slip area of the 2004 Kushiro-oki earthquake was estimated to be just at the northwestern edge of that of the 1973 Nemuro-oki earthquake. We speculated that the area of the 2004 Kushiro-oki earthquake acted as a barrier during the 1973 Nemuro-oki earthquake.

(5) The postseismic deformation of the 1973 Nemuro-oki earthquake was characterized by short-term and longterm deformation. Based on the tide-gauge data from Nemuro (Hanasaki), the short-term deformation could be attributed to rapid uplift over $\sim 1.5$ years, and the long-term deformation was attributed to no vertical displacement deviation from the interseismic subsidence for more than 10 years. The afterslip distribution for the short-term deformation was partly resolved by the geodetic data. It is suggested that the afterslip occurred at least in a western and deep extension of the asperity on the plate interface.

Acknowledgments. The author appreciates Profs. Jeff Freymueller, Yuichiro Tanioka, and Takeshi Sagiya (associate editor) for careful reviews and useful comments. We also thank the Japan Meteorological Agency for providing their earthquake catalogue. This work was supported by a Grant-in-Aid for Young Scientists (B) (KAKENHI) 18740282.

\section{References}

Akaike, H., Likelihood and the Bayes procedure, in Bayesian Statistics, edited by J. M. Bernardo, M. H. DeGroot, D. V. Lindley, and A. F. M. Smith, 143-166, University Press, Valencia, 1980.

Baba, T., K. Hirata, T. Hori, and H. Sakaguchi, Offshore geodetic data conducive to the estimation of the afterslip distribution following the 2003 Tokachi-oki earthquake, Earth Planet. Sci. Lett., 241, 281-292, 2006.

DeMets, C., R. G. Gordon, D. F. Argus, and S. Stein, Effect of recent revisions to the geomagnetic reversal time scale on estimates of current plate motions, Geophys. Res. Lett., 21, 2191-2194, 1994.

Fukao, Y. and M. Furumoto, Foreshocks and multiple shocks of large earthquakes, Phys. Earth Planet. Inter., 10, 355-368, 1975.

Geographical Survey Institute, Crustal deformations of Entire Japan, Rep. Coord. Comm. Earthq. Predict., 80, 5-27, 2008 (in Japanese).

Hashimoto, M. and T. Tada, Horizontal crustal movements in Hokkaido and its tectonic implications, J. Seismol. Soc. Jpn. (Zisin), 41, 29-38, 1988 (in Japanese with English abstract).

Headquarters for Earthquake Research Promotion, Long-term evaluation for seismic activities along the Chishima (Kuril) Trench (2nd Ed.), http://www.jishin.go.jp/main/chousa/04dec_chishima2/index.htm, 2004.
Heki, K., S. Miyazaki, and H. Tsuji, Silent fault slip following an interplate thrust earthquake at the Japan Trench, Nature, 386, 595-598, 1997.

Hirata, K., E. Geist, K. Satake, Y. Tanioka, and S. Yamaki, Slip distribution of the 1952 Tokachi-oki earthquake (M8.1) along the Kuril trench deduced from tsunami waveform inversion, J. Geophys. Res., 108(B4), 2196, doi:10.1029/2002JB001976, 2003.

Kasahara, K. and T. Kato, Aseismic faulting following the 1973 Nemurooki earthquake, Hokkaido, Japan (a Retrospective Study), Pure Appl. Geophys., 157, 392-403, 1980.

Kato, T. and K. Tsumura, Vertical land movement in Japan as deduced from tidal record, Bull Earthq. Res. Inst., Univ. Tokyo, 54, 559-628, 1979 (in Japanese with English abstract).

Katsumata, K. and Y. Yamanaka, The 29 November 2004 M7.1 Kushirooki earthquake: An event between the on-going seismic quiescence area and the asperity ruptured by the 1973 Nemuro-oki earthquake, Geophys. Bull. Hokkaido Univ., 69, 23-39, 2006.

Katsumata, K., N. Wada, and M. Kasahara, Newly imaged shape of the deep seismic zone within the subducting Pacific plate beneath the Hokkaido corner, Japan-Kurile arc-arc junction, J. Geophys. Res., 108(B12), 2565, doi:10.1029/2002JB002175, 2003.

Kikuchi, M. and Y. Fukao, Inversion of long-period P-waves from great earthquakes along subduction zones, Tectonophysics, 144, 231-247, 1987.

Komaki, K., Horizontal crustal movements revealed by geodetic measurements-Applications of a new method for estimating displacement vectors-, J. Geod. Soc. Jpn., 39, 387-410, 1993.

Miura, S., Y. Suwa, A. Hasegawa, and T. Nishimura, The 2003 M8.0 Tokachi-oki earthquake? How much has the great event paid back slip debts?, Geophys. Res. Lett., 31, L05613, doi:10.1029/2003GL019021, 2004.

Miyazaki, S. and K. M. Larson, Coseismic and early postseismic slip for the 2003 Tokachi-oki earthquake sequence inferred from GPS data, Geophys. Res. Lett., 35, L04302, doi:10.1029/2007GL032309, 2008.

Nagai, R., M. Kikuchi, and Y. Yamanaka, Comparative study on the source process of recurrent large earthquakes in Sanriku-Oki region: The 1968 Tokachi-Oki earthquake and the 1994 Sanriku-oki earthquake, J. Seismol. Soc. Jpn. (Zisin), 52, 267-289, 2001 (in Japanese with English abstract).

Nakanishi, A., A. J. Smith, S. Miura, T. Tsuru, S. Kodaira, K. Obana, N. Takahashi, P. R. Cummins, and Y. Kaneda, Structural factors controlling the coseismic rupture zone of the 1973 Nemuro-Oki earthquake, the southern Kuril Trench seismogenic zone, J. Geophys. Res., 109, B05305, doi:10.1029/2003JB002574, 2004.

Namegaya, Y. and Y. Tsuji, Delayed peaks of tsunami waveforms at Miyako from earthquakes east off Hokkaido, in Tsunamis: Case Studies and Recent Developments, edited by K. Satake, 115-134, Springer, Netherlands, 2005.

Nanayama, F., K. Satake, R. Furukawa, K. Shimokawa, B. F. Atwater, K. Shigeno, and S. Yamaki, Unusually large earthquakes inferred from tsunami deposits along the Kuril trench, Nature, 424, 660-663, 2003.

Nishimura, T., Fault model of the 1952 Tokachi-oki earthquake induced from geodetic data, Earth Monthly, 28, 441-447, 2006 (in Japanese).

Nishimura, T., T. Hirasawa, S. Miyazaki, T. Sagiya, T. Tada, S. Miura, and K. Tanaka, Temporal change of interplate coupling in northeastern Japan during 1995-2002 estimated from continuous GPS observations, Geophys. J. Int., 157, 901-916, 2004.

Nyst, M., T. Nishimura, F. F. Pollitz, and W. Thatcher, Inference of postseismic deformation mechanisms of the 1923 Kanto earthquake, J. Geophys. Res., 111, B05408, doi:10.1029/2005JB003901, 2006.

Okada, T., Surface deformation due to shear and tensile faults in a halfspace, Bull. Seismol. Soc. Am., 75, 1135-1154, 1985.

Oleskevich, D. A., R. D. Hyndman, and K. Wang, The updip and downdip limits to great subduction earthquakes: Thermal and structural models of Cascadia, south Alaska, SW Japan, and Chile, J. Geophys. Res., 104(B7), 14965-14991, 1999.

Ozawa, S., Geodetic inversion for the fault model of the 1994 Shikotan earthquake, Geophys. Res. Lett., 23, 2009-2012, 1996.

Ozawa, S., M. Kaidzu, M. Murakami, T. Imakiire, and Y. Hatanaka, Coseismic crustal deformation after the Mw8 Tokachi-oki earthquake in Japan, Earth Planets Space, 56, 675-680, 2004.

Sagiya, T. and W. Thatcher, Coseismic slip resolution along a plate boundary megathrust: The Nankai trough, southwest Japan, J. Geophys. Res., 104, 1111-1129, 1999.

Sagiya, T., S. Miyazaki, and T. Tada, Continuous GPS array and presentday crustal deformation of Japan, Pure Appl. Geophys., 157, 23032322, 2000. 
Satake, K., K. Hirata, S. Yamaki, and Y. Tanioka, Re-estimation of tsunami source of the 1952 Tokachi-oki earthquake, Earth Planets Space, 58, 535-542, 2006.

Satake, K., F. Nanayama, and S. Yamaki, Fault models of unusual tsunami in the 17th century along the Kuril trench, Earth Planets Space, 60, 925-935, 2008.

Sella, G. F., T. Dixon, and A. Mao, REVEL: A model for recent plate velocities from space geodesy, J. Geophys. Res., 107(B4), doi10.1092/ 2000JB000033, 2002.

Seno, T., Variation of downdip limit of the seismogenic zone near the Japanese islands: Implications for the serpentinization mechanism of the forearc mantle wedge, Earth Planet. Sci. Lett., 231, 249-262, 2005.

Shen, Z., D. D. Jackson, and B. X. Ge, Crustal deformation across and beyond the Los Angeles Basin from geodetic measurements, J. Geophys. Res., 101, 27957-27980, 1996.

Shimazaki, K., Nemuro-oki earthquake of June 17, 1973: A lithospheric rebound at the upper half of the interface, Phys. Earth Planet. Inter., 9, 314-327, 1974.

Suwa, Y., S. Miura, A. Hasegawa, T. Sato, and K. Tachibana, Interplate coupling beneath NE Japan inferred from three-dimensional displacement field, J. Geophys. Res., 111, B04402, doi:10.1029/2004JB003203, 2006.

Tada, T., Fault model and crustal movement of the 1973 Nemuro-oki Earthquake, J. Seismol. Soc. Jpn.(Zisin), 27, 120-128, 1974 (in Japanese with
English abstract).

Tanioka, Y., K. Hirata, R. Hino, and T. Kanazawa, Slip distribution of the 2003 Tokachi-oki earthquake estimated from tsunami waveform inversion, Earth Planets Space, 56, 373-376, 2004.

Tanioka, Y., K. Satake, and K. Hirata, Recurrence of recent large earthquakes along the southernmost Kurile-Kamchatka Subduction zone, in Geophysical Monograph, 172, 145-152, AGU, Washington D.C., 2007. Utsu, T., Large earthquakes near Hokkaido and the expectancy of the occurrence of a large earthquake off Nemuro, Rep. Coord. Comm. Earthq. Predict., 7, 7-13, 1972 (in Japanese).

Yamanaka, Y., Asperity map in Hokkaido and southern Kurile arc, Earth Monthly, 28, 427-431, 2006 (in Japanese).

Yamanaka, Y. and M. Kikuchi, Source process of the recurrent Tokachioki earthquake on September 26, 2003, inferred from teleseismic body waves, Earth Planets Space, 55, e21-e24, 2003.

Yamanaka, Y. and M. Kikuchi, Asperity map along the subduction zone in northeastern Japan inferred from regional seismic data, J. Geophys. Res., 109, B07307, doi10.1092/2003JB002683, 2004.

Yoshida, S., A. Kato, N. Kato, and M. Nakatani, Interpretation of various slip modes on a plate boundary based on laboratory and numerical experiments, Earth Planets Space, 56, 795-801, 2004.

T. Nishimura (e-mail: t_nisimura@gsi.go.jp) 